\title{
Effects of designed PLLA and 50:50 PLGA scaffold architectures on bone formation in vivo
}

\author{
Eiji Saito ${ }^{1}$, Elly E. Liao ${ }^{1}$, Wei-Wen $\mathrm{Hu}^{5}$, Paul H. Krebsbach ${ }^{1,2}$ and Scott J. Hollister ${ }^{1,3,4 *}$ \\ ${ }^{1}$ Department of Biomedical Engineering, University of Michigan, Ann Arbor, Michigan, 48109-2099, USA \\ ${ }^{2}$ Department of Biologic and Materials Science, School of Dentistry, University of Michigan, Ann Arbor, Michigan, 48109-1078, USA \\ ${ }^{3}$ Department of Mechanical Engineering, University of Michigan, Ann Arbor, Michigan 48109-2125, USA \\ ${ }^{4}$ Department of Surgery, University of Michigan, Ann Arbor, Michigan, 48109-0329, USA \\ ${ }^{5}$ Department of Chemical and Materials Engineering, National Central University, Jhongli, Taoyuan, Taiwan
}

\begin{abstract}
Biodegradable porous scaffolds have been investigated as an alternative approach to current metal, ceramic, and polymer bone graft substitutes for lost or damaged bone tissues. Although there have been many studies investigating the effects of scaffold architecture on bone formation, many of these scaffolds were fabricated using conventional methods such as salt leaching and phase separation, and were constructed without designed architecture. To study the effects of both designed architecture and material on bone formation, this study designed and fabricated three types of porous scaffold architecture from two biodegradable materials, poly (L-lactic acid) (PLLA) and 50:50 Poly(lactic-co-glycolic acid) (PLGA), using image based design and indirect solid freeform fabrication techniques, seeded them with bone morphogenetic protein-7 transduced human gingival fibroblasts, and implanted them subcutaneously into mice for 4 and 8 weeks. Microcomputed tomography data confirmed that the fabricated porous scaffolds replicated the designed architectures. Histological analysis revealed that the 50:50 PLGA scaffolds degraded but did not maintain their architecture after 4 weeks implantation. However, PLLA scaffolds maintained their architecture at both time points and showed improved bone ingrowth, which followed the internal architecture of the scaffolds. Mechanical properties of both PLLA and 50:50 PLGA scaffolds decreased but PLLA scaffolds maintained greater mechanical properties than 50:50 PLGA after implantation. The increase of mineralized tissue helped support the mechanical properties of bone tissue and scaffold constructs between 4-8 weeks. The results indicate the importance of choice of scaffold materials and computationally designed scaffolds to control tissue formation and mechanical properties for desired bone tissue regeneration. Copyright (c) 2011 John Wiley \& Sons, Ltd.
\end{abstract}

Received 15 September 2010; Revised 2 March 2011; Accepted 12 July 2011

Keywords scaffold; designed architecture; poly (L-lactic acid); poly (lactic-co-glycolic acid); degradation; bone regeneration; solid freeform fabrication

\section{Introduction}

Bone graft substitutes such as titanium and other metals have been used for reconstructing bone defects caused by injury, inflammatory disease, and cancer. However, these implants are less than ideal because the materials are non-degradable and can cause stress shielding. Tissue-engineered scaffolds have been

*Correspondence to: Scott J. Hollister, Department of Biomedical Engineering, University of Michigan, Ann Arbor, Michigan 48109-2099, USA. E-Mail: scottho@umich.edu studied as alternative implants to heal skeletal defects. To enhance bone tissue integration and bone growth into tissue-engineered scaffolds, scaffolds should have a porous architecture to encourage cell migration and blood vessel formation (Karageorgiou and Kaplan, 2005). It is also necessary that they have sufficient mechanical properties to support physiologic loading and proper degradation profiles to transfer loads to regenerating tissues during healing (Athanasiou et al., 1998; Hutmacher, 2001; Hollister, 2005).

Poly(L-lactic acid) (PLLA) and Poly(lactic-co-glycolic acid) (PLGA) have both been approved by the FDA for 
specific clinical indications (Middleton and Tipton, 2000). They have been successfully used as orthopaedic implants (Athanasiou et al., 1998; Kontakis et al., 2007) and have been widely studied as scaffolds for bone regeneration both in vitro and in vivo. Due to different degrees of hydrophilicity, degradation ratios, and by-products, PLLA and PLGA have different effects on cell behaviour and tissue regeneration, and have been compared in different matrices including films, porous sponges, and fibre like shapes using various cell types (Narayan and Venkatraman, 2008; Li et al., 2006; Kaushiva et al., 2007; Ishaug-Riley et al., 1999). It has been shown that degradation time changes depending on the ratio of lactic acid and glycolic acid polymer (Li et al., 2006; Kaushiva et al., 2007; Lu et al., 2000). Therefore, adjusting the polymer ratio should control the degradation time of these scaffolds and their distinct degradation profiles could influence bone regeneration.

In addition to scaffold material composition, factors influencing scaffold architecture such as porosity and pore size play a critical role in cell migration and bone formation into the scaffolds (Gomes et al., 2006; Khan et al., 2008). It has been postulated that $\mathrm{a} \sim 100-\mu \mathrm{m}$ pore diameter is suitable for in vitro cell migration and a $300-\mu \mathrm{m}$ pore diameter is necessary for tissue ingrowth and nutrient diffusion (Karageorgiou and Kaplan, 2005; Cao et al., 2006). However, the effects of scaffold architecture on bone tissue formation are not fully understood and vary significantly between studies (Schek et al., 2006; Li et al., 2007; Rose et al., 2004; Tsuruga et al., 1997; Kuboki et al., 2001; Ishaug-Riley et al., 1997; Ishaug-Riley et al., 1998; Wu et al., 2006). Because the effects of scaffold architecture on bone formation can differ depending on the materials studied (Wu et al., 2006, Sinha et al., 1994) and the ability to fabricate scaffolds with controlled pore architectures (Melchels et al., 2010), it is necessary to investigate the effects of rigorously controlled architectures for each biodegradable scaffold to clearly delineate architecture versus material influence on bone regeneration.

Conventional biodegradable scaffolds, especially scaffolds made from PLLA and PLGA, have been commonly fabricated by salt leaching or gas foaming and have a wide range of pore sizes with poor or noninterconnected pores, and the scaffold architectures are not identically duplicated with repeated samples (Hsu et al., 2007; Hutmacher et al., 2001). It is also difficult to control local pore and wall locations and porosities of these scaffolds. Currently, scaffold architecture is controlled at the global or overall scaffold level. Furthermore, to ensure pore interconnectivity, porosity needs to be increased and as a result, the mechanical properties of scaffolds could thereby be reduced (Goldstein et al., 1999).

To overcome these limitations, the combination of computer aided design and solid freeform fabrication techniques have been developed (Hollister, 2005; Sun et al., 2004, Hutmacher et al., 2004, Martins et al.,
2009). These methods allow the design and fabrication of scaffolds with controllable local pore architecture to generate reproducible and effective mechanical and mass transport properties. The current authors developed image-based design techniques by which the internal architectures of scaffolds could be customized based on the mathematical concept of unit cells (Hollister et al., 2000; Hollister et al., 2002; Lin et al., 2004). These unit cells were designed and fabricated to have the desired effective physical properties such as compressive modulus, permeability, and diffusivity. Furthermore, the indirect solid freeform fabrication (SFF) method was used to fabricate scaffolds with designed pore diameters, struts sizes, and porosities (Taboas et al., 2003). Using these techniques, the authors successfully designed and fabricated 50:50 PLGA porous scaffolds with compression moduli within the range of human trabecular bone (Saito et al., 2010).

Bone morphogenetic proteins (BMPs) belong to the TGF- $\beta$ family and have been extensively applied using direct BMP delivery or in vivo or ex vivo delivery via gene therapy to induce bone formation for skeletal regeneration (Bessa et al., 2008a; Bessa et al., 2008b; Nussenbaum and Krebsbach, 2006). The current study method selected to express BMPs in vivo used human dermal and gingival fibroblasts that were transduced by recombinant adenovirus encoding BMPs to induce bone formation in ectopic sites (Rutherford et al., 1992; Krebsbach et al., 2000). This technique was combined with porous SFF scaffolds to facilitate bone generation (Schek et al., 2006; Williams et al., 2005; Lin et al., 2005; Roosa et al., 2010). As a result, this ex vivo gene therapy method was applied to induce bone formation in the engineered scaffolds.

The goal of this study was to determine the influence of scaffold material and architecture, especially pore size, strut size, and surface/volume ratios on bone formation in vivo, and to evaluate the mechanical properties of the resulting scaffolds and tissue constructs. Six groups of scaffolds (three different designs and two different materials; PLLA and 50:50 PLGA scaffolds) were fabricated. The scaffolds were seeded with transduced human gingival fibroblasts expressing BMP-7 and then implanted into mice subcutaneous pockets for 4 and 8 weeks. The scaffolds and scaffold-regenerated bone tissue constructs were evaluated using micro-computed tomography ( $\mu$-CT), mechanical testing, and histological assessments.

\section{Methods}

\subsection{Porous scaffold design and fabrication}

Porous scaffolds $5 \mathrm{~mm}$ in diameter and $3 \mathrm{~mm}$ high with three different pore diameters (280, 550, and $820 \mu \mathrm{m})$ were designed using image-based techniques (Figure 1a). Based on the designed pore sizes, each group of scaffolds was named large (pore size $=820 \mu \mathrm{m}$ ), medium (pore size $=550 \mu \mathrm{m})$, or small $($ pore size $=280 \mu \mathrm{m})$. First, the 
(a)
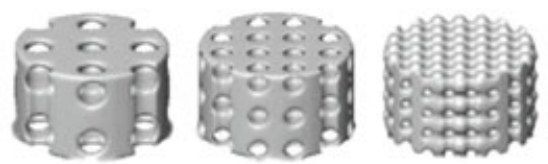

(b)

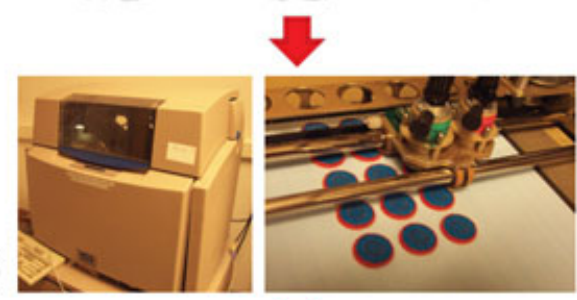

(c)

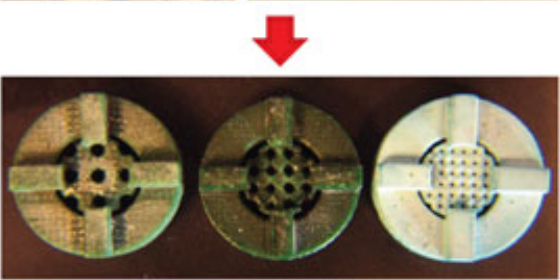

(d)
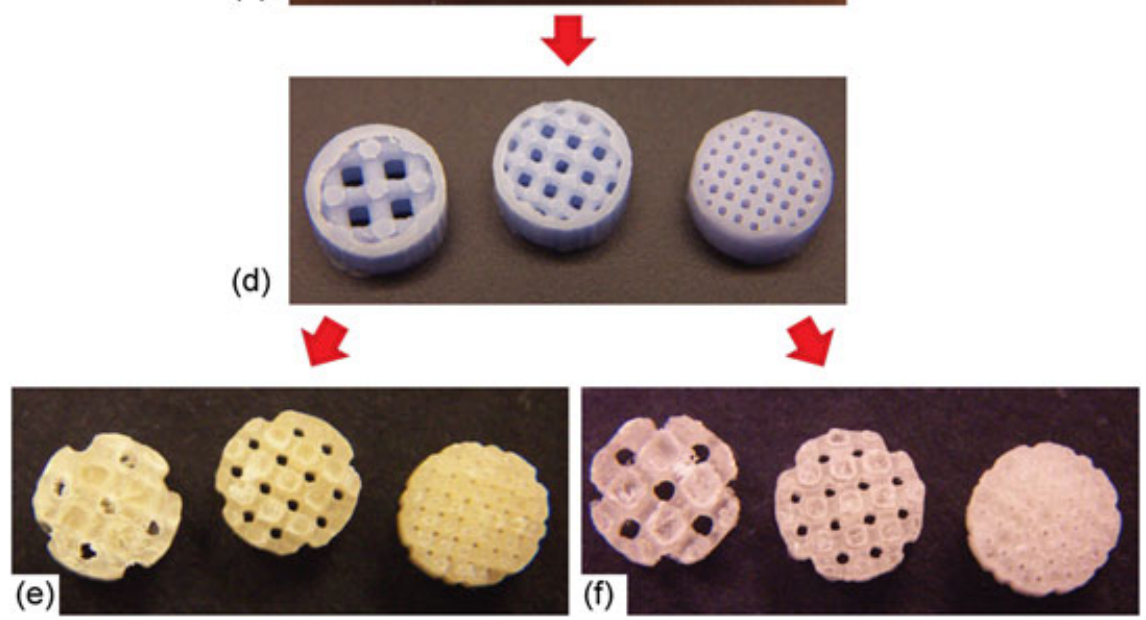

Figure 1. Porous scaffolds were designed using image based design techniques and exported into STL formats (Large, Medium and Small, from left to right) (a). The stl format files were imported to the rapid prototyping machines (b) to print the thermoplastic molds (c). The thermoplastic molds were casted into HA secondary molds (d), and finally the HA secondary molds were casted into either PLLA scaffolds (e) or 50:50 PLGA scaffolds (f)

unit cells of each design were determined, and then generated in a repeating pattern to fill the external scaffold geometry. The resulting image representations were converted to stereolithography (STL) formats and sliced using Modelworks software (Solidscape Inc., Merrimack, $\mathrm{NH}$, USA) to fabricate wax molds using a ModelMaker II for large and medium scaffolds and PatternMaster ${ }^{\mathrm{TM}}$ (Figure 1b) for small scaffolds 3D printer (Solidscape). The wax molds (Figure 1c) were cast into hydroxyapatite ceramic (HA) secondary molds (Figure $1 \mathrm{~d}$ ). Next, polymer pellets PLLA (inherent viscosity $=0.65 \mathrm{dl} / \mathrm{g}$ ) and 50:50 PLGA (inherent viscosity $=0.61 \mathrm{dl} / \mathrm{g}$ ) (Birmingham Polymers Inc., Birmingham, AL, USA) were heated at $205^{\circ} \mathrm{C}$ and $170^{\circ} \mathrm{C}$, respectively in a Teflon mold. The HA molds were then placed into the Teflon mold containing molten polymer to force the polymer through the open pore network. The HA molds were then removed from the porous polymer scaffolds using RDO Rapid Decalcifier (APEX Engineering Products Corp, Plainfield, IL, USA). The scaffolds were then sterilized in 70\% ethanol overnight and left in $100 \%$ ethanol until the day of implantation.

\subsection{Cell preparation and scaffold implantation}

Primary human gingival fibroblasts (HGFs) were prepared from explants of human surgical waste in compliance with the University of Michigan Institutional Review Board (Rutherford et al., 1992). HGFs from passage 5-10 were cultured near confluence in Alpha minimum essential medium ( $\alpha$-MEM) supplemented with $10 \%$ foetal bovine serum and $1 \%$ penicillin and streptomycin $\left(\mathrm{Gibco}^{\circledR}\right.$; Invitrogen, Carlsbad, CA, USA). 24h before implantation, the HGFs were infected with AdCMV-BMP7, a recombinant adenovirus construct expressing murine BMP-7 gene, under a cytomegalovirus (CMV) promoter at a multiplicity of infection (MOI) of $1000 \mathrm{PFU} / \mathrm{cell}$ (Franceschi et al., 2000). Two million cells were seeded into each scaffold by suspending them in $60 \mu \mathrm{l}$ of $5 \mathrm{mg} / \mathrm{ml}$ bovine plasmaderived fibrinogen (Sigma-Aldrich Corp., St-Louis, MO, USA) and gelled with $6 \mu \mathrm{l}$ of $100 \mathrm{U} / \mathrm{ml}$ bovine plasmaderived thrombin (Sigma). The scaffolds were subcutaneously implanted into immunocompromised NIH-bg-nu-xid mice (Charles River, Wilmington, MA, USA). After the 
animals were anesthetized with an injection of ketamine/ xylazine, four subcutaneous pockets were created and four scaffolds were implanted into each mouse, and finally, surgical sites were closed with wound clips in compliance with the University Committee on the Use and Care of Animal (UCUCA) regulations. The mice were sacrificed at 4 and 8 weeks after implantation and the scaffold and tissue constructs were harvested, fixed with Z-fix (Anatech Ltd., Battle Creek, MI, USA), and left in 70\% ethanol for further assays.

\subsection{Scaffold and regenerated tissue assays}

All scaffolds (pre-implantation alone and post-implantation with tissues) were scanned using a MS-130 high resolution $\mu$-CT Scanner (GE Medical Systems, Toronto, Canada) at a resolution of $16 \mu \mathrm{m}$. The scanned images were reconstructed using MicroView software (GE). The reconstructed images were used to calculate scaffold pore size, porosity, and surface area prior to implantation, and bone volume (BV) and tissue mineral density (TMD) were calculated for the scaffolds after implantation. The surfaces of pre-implanted scaffolds were also examined under a Philips XL30 ESEM scanning electron microscope (Phillips, Andover, MA, USA). The environmental scanning electron microscopy (ESEM) mode was carried out at $10 \mathrm{kV}$ and in a humid atmosphere of 0.7 Torr.

\subsection{Mechanical test of scaffolds with regenerated tissue}

Following $\mu$-CT scanning, 4-7 replicates from each scaffold group were mechanically tested. Compression tests were performed after scaffolds were rehydrated for $30 \mathrm{~min}$ using a MTS alliance RT/30 electromechanical test frame (MTS Systems Corp., Eden Prairie, MN, USA). The crosshead speed was $1 \mathrm{~mm} / \mathrm{min}$ after a preload of $0.227 \mathrm{~kg}(0.5 \mathrm{lbs})$ for PLLA scaffolds and 0.0227 kg (0.05 lbs) for 50:50 PLGA scaffolds. The heights of the scaffolds were measured with a caliper, and TestWorks $4^{\circledR}$ software (MTS Systems Corp.) was used to record load and displacement data. The stress-strain curves were calculated from the initial dimensions of the specimens. The compressive modulus was defined by the slope at the initial linear section of the stress-strain curve.

\subsection{Histological analysis}

After $\mu$-CT scanning, one harvested scaffold from each group was used for histological assay. The scaffold and tissue constructs were demineralized with RDO and the residual polymer in the tissue was removed using chloroform prior to paraffin embedding. The scaffolds were then sectioned at $5 \mu \mathrm{m}$ and stained with hematoxylin and eosin (H\&E).

\subsection{Statistical analysis}

Statistical analysis was performed with SPSS (SPSS Inc., Chicago, IL, USA). Two groups were analyzed with Student's $t$-test for independent samples. Multiple comparison procedures were determined by One-Way ANOVA followed by Tukey's Post-Hoc multiple comparisons. Errors were reported as the standard deviation (SD) and significance was determined using a probability value of $p<0.05$.

\section{Results}

\subsection{Evaluation of the fabricated (pre-implanted) scaffolds}

The schematics of the design and fabrication process of the scaffolds are depicted in Figure 1. HA secondary molds (Figure $1 \mathrm{~d}$ ) ensured that the fabrication process was identical between PLLA and 50:50 PLGA scaffolds, except for polymer casting temperatures. The architecture of the designs was the same for both fabricated PLLA and 50:50 PLGA scaffolds (Figures 1e, 1f), which was also confirmed by $\mu$-CT rendering images (Figures 2a-f). The orthogonal pore locations and connections of the fabricated PLLA and 50:50 PLGA scaffolds were also confirmed from the cross-sectional images of $\mu$-CT data (Figures $2 \mathrm{~g}-1$ ). Low magnification ESEM images were similar in all groups (Figures 2m-r), while the high magnification images showed slightly rougher surfaces on the PLLA scaffolds than the 50:50 PLGA scaffolds (Figures 2s-x, indicated by stars). Furthermore, porosity, surface to volume ratio, pore size, and strut size were measured using the $\mu$-CT images (Table 1). For each parameter, there was no significant difference between the fabricated PLLA and 50:50 PLGA scaffolds. These data support the concept that the scaffold architectures within each design group (large, medium, small) made of the two materials were identical to each other. Porosity, pore size, and strut size of the fabricated scaffolds decreased in order from large to small pore designs. The small group had a higher surface to volume ratio than the large and medium groups for both PLLA and 50:50 PLGA scaffolds.

\subsection{Histological observations of implanted scaffolds}

Due to the secretion of BMP-7 from the transduced HGFs, all implanted scaffolds had bone-like tissue formation after 4 and 8 weeks (Figure 3). Histological images of cortical bone-like tissues forming outer layers and bone marrow-like tissues such as trabecular structures, endothelial cells, and osteoblasts were observed within the cortical layer and the scaffolds. In the 

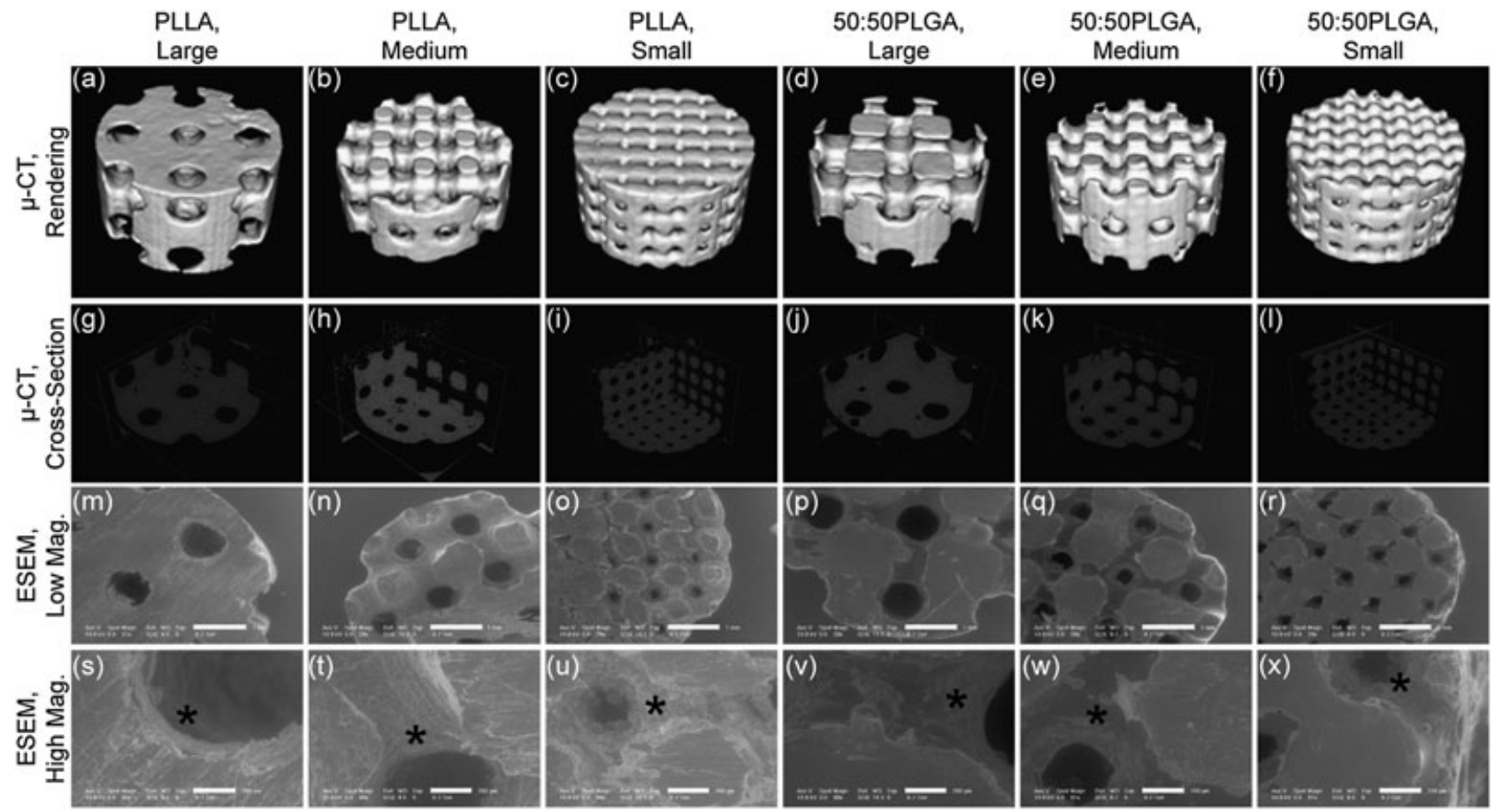

Figure 2. $\mu$-CT rendering images (a-f), $\mu$-CT images showing cross sectional $\mathrm{x}, \mathrm{y}$, and $\mathrm{z}$ planes ( $\mathrm{g}-\mathrm{l}$ ), and ESEM images of fabricated PLLA and 50:50 PLGA scaffolds (m-x). The scale bars in the ESEM images are $1 \mathrm{~mm}$ and $200 \mu \mathrm{m}$ for Low (m-r) and High magnifications (s-x), respectively. * indicates the surface around the pores for comparison of the surface morphologies of PLLA and 50:50 PLGA scaffolds

Table 1. Fabricated scaffold dimensions

\begin{tabular}{|c|c|c|c|c|c|c|}
\hline & \multicolumn{3}{|c|}{ PLLA } & \multicolumn{3}{|c|}{ 50:50 PLGA } \\
\hline & Large & Medium & Small & Large & Medium & Small \\
\hline Pore size $(\mathrm{mm})$ & $0.821 \pm 0.041$ & $0.580 \pm 0.039$ & $0.285 \pm 0.026$ & $0.840 \pm 0.057$ & $0.537 \pm 0.033$ & $0.258 \pm 0.037$ \\
\hline Strut size (mm) & $0.914 \pm 0.028$ & $0.594 \pm 0.033$ & $0.413 \pm 0.017$ & $0.898 \pm 0.045$ & $0.622 \pm 0.050$ & $0.448 \pm 0.039$ \\
\hline Porosity (\%) & $52.1 \pm 0.95$ & $45.4 \pm 3.21$ & $32.1 \pm 3.50$ & $52.9 \pm 2.17$ & $43.8 \pm 2.21$ & $30.5 \pm 3.30$ \\
\hline Surface/Volume $\left(\mathrm{mm}^{2} / \mathrm{mm}^{3}\right)$ & $4.57 \pm 0.22$ & $4.54 \pm 0.15$ & $5.40 \pm 0.17$ & $4.65 \pm 0.25$ & $4.88 \pm 0.31$ & $5.43 \pm 0.59$ \\
\hline
\end{tabular}

4-week implant groups, most of the marrow-like tissues were distributed in the peripheral regions of the specimen. However, more bone marrow-like tissues containing blood vessel-like tissues were observed in the 8-week than in 4-week implants. Marrow-like tissue was found both at the centre of the scaffolds and in the surrounding regions at 8 weeks.

Histological images also show that tissue formation differed between PLLA and 50:50 PLGA scaffold groups. After 4 weeks implantation, little degradation of PLLA was observed and most of their architectures remained intact (Figures 3a-c). However, 50:50 PLGA scaffolds degraded much rapidly and lost their initial architectures (Figures 3d-f). After 8 weeks implantation, PLLA scaffolds maintained their architecture, while most of 50:50 PLGA degraded, leaving very little polymer, and the bone constructs appeared flattened (Figures 3h-m). After degradation of most of the 50:50 PLGA scaffolds, histological images showed more bone marrow-like tissues containing blood vessel-like tissues in the 8-week compared to the 4-week implants. For PLLA scaffolds, bone-like tissues formed mostly in the peripheral area of the scaffolds and very little bone ingrowth was observed (Figures 3a-c and $3 \mathrm{~g}$ ), and a few blood vessel-like tissues were seen inside of the scaffolds (Figure $3 \mathrm{~g}$ ) at 4 weeks. At 8 weeks, advanced bone ingrowth was observed following the porous architectures of the small PLLA scaffolds (Figure 3j), and larger blood vessel tissues were also observed (Figure 3n). In addition, there might have been more fibrous tissue on PLLA scaffolds at week 4 than week 8.

\subsection{Tissue observations using $\mu-\mathrm{CT}$}

3D tissue representations were generated from $\mu$-CT data (Figure 4). Mineralized tissues were highlighted and colour contours indicated the density of the regenerated tissues. Highly dense tissues were distributed only on the 


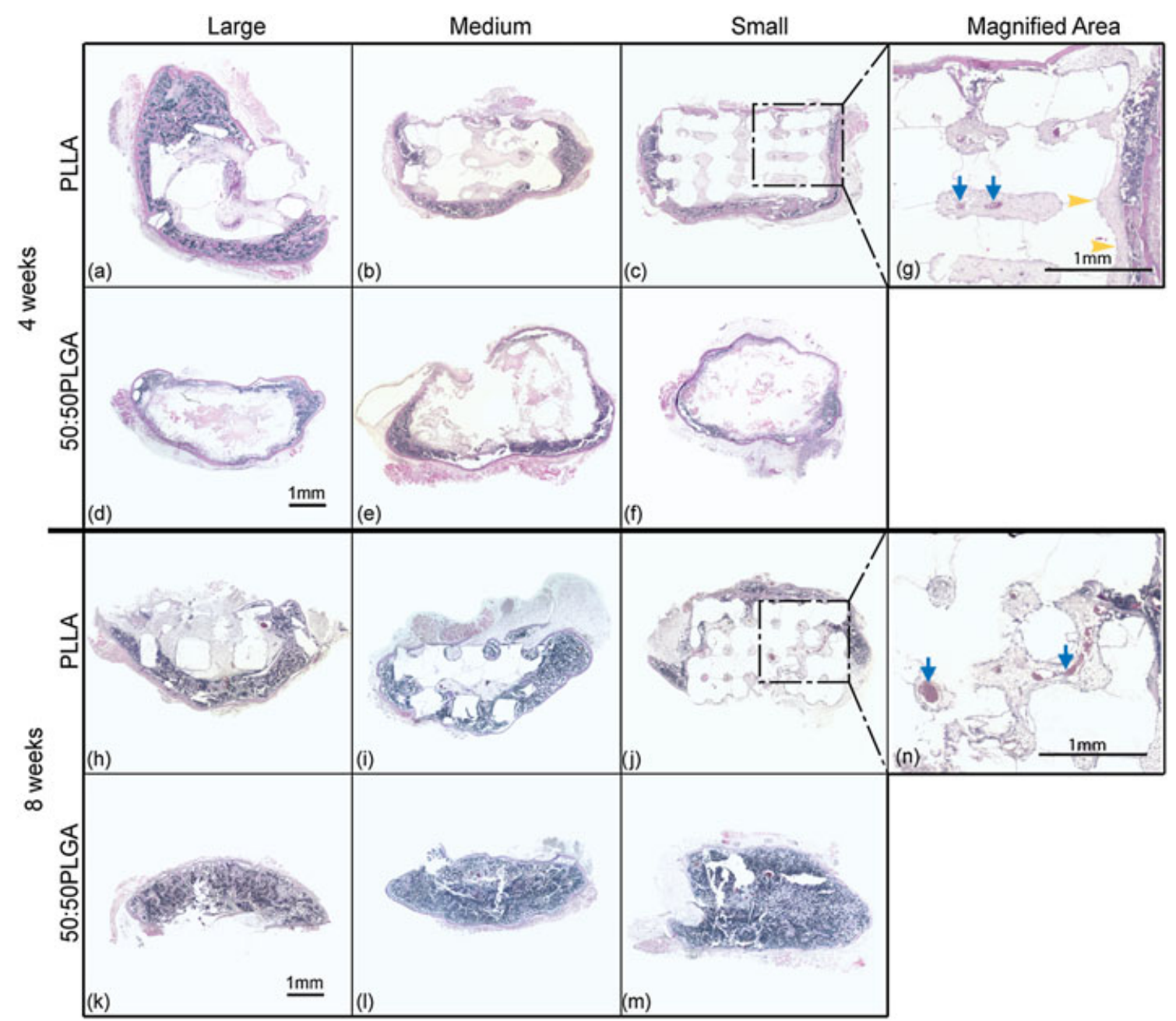

Figure 3. Histological images of PLLA (a, b, and c) and 50:50 PLGA scaffolds (d, e, and f) at 4 weeks and PLLA (h, i and j) and 50:50 PLGA scaffolds ( $\mathrm{k}, 1$, and $\mathrm{m}$ ) at 8 weeks. Porous architectures of PLLA scaffolds were maintained for all groups (a, b, and c) at 4 weeks and (h, i, and j) at 8 weeks. None of 50:50 PLGA groups maintained the initial architectures, however, polymer material was still left inside of the bony shells at 4 weeks (d, e, and f). After 8 weeks, most of 50:50 PLGA polymer had degraded and disappeared (k, 1 , and $\mathrm{m}$ ). Magnified areas of Small PLLA scaffold at 4 weeks (c) were shown (h: dashed-dotted line). Yellow arrow indicates fibrous tissue between scaffold and trabecular like tissue, and a few blood vessel-like tissues were indicated by blue arrows (g). Magnified areas of Small PLLA scaffold at 8 weeks (j) were also shown (n: dashed-dotted line). Thicker blood vessel-like tissues were observed within the scaffold pores, shown by blue arrows (n)

outside of the scaffolds. Due to rapid degradation, there was no bone growth into the 50:50 PLGA scaffolds. All PLLA scaffolds maintained their architecture at all time points. There was some bone ingrowth into the PLLA scaffolds at 4 weeks, while there was slightly more bone ingrowth at 8 weeks. Maximum bone penetration was measured as the distance from the circular peripheral edge of each scaffold towards the centre $(\mathrm{N}=3-5$ scaffolds). Bone penetration in the small, medium, and large PLLA scaffolds was $0.464 \pm 0.024 \mathrm{~mm}$, $0.723 \pm 0.392 \mathrm{~mm}$, and $0.457 \pm 0.146 \mathrm{~mm}$, respectively at 4 weeks, and $1.043 \pm 0.292 \mathrm{~mm}, 0.834 \pm 0.249 \mathrm{~mm}$, and $0.773 \pm 0.049 \mathrm{~mm}$, respectively at 8 weeks. Small PLLA scaffolds supported a significant increase of bone penetration between weeks 4 and 8. Large and medium PLLA scaffolds also had increases in bone penetration but these did not reach a statistically significant level. There was no significant difference between the scaffold groups at each time point. In addition, the pattern of bone ingrowth followed the internal scaffold architectures and bone tissues regenerated along the struts (Figures 4g-i). More bone tissue distribution was observed at 8 weeks than at 4 weeks, with the highest amounts seen in the small PLLA group, which had more bone surrounding the struts (Figure 4i).

\subsection{Tissue mineral density and bone volume of implanted scaffolds}

TMD and BV were also calculated using $\mu$-CT data (Figure 5, Table 2). The data demonstrated that TMD significantly increased in all groups between 4- and 8-week implantation. From the 4-week implantation data, although there was no significant difference, the small PLLA scaffold group had higher TMD than the large and 


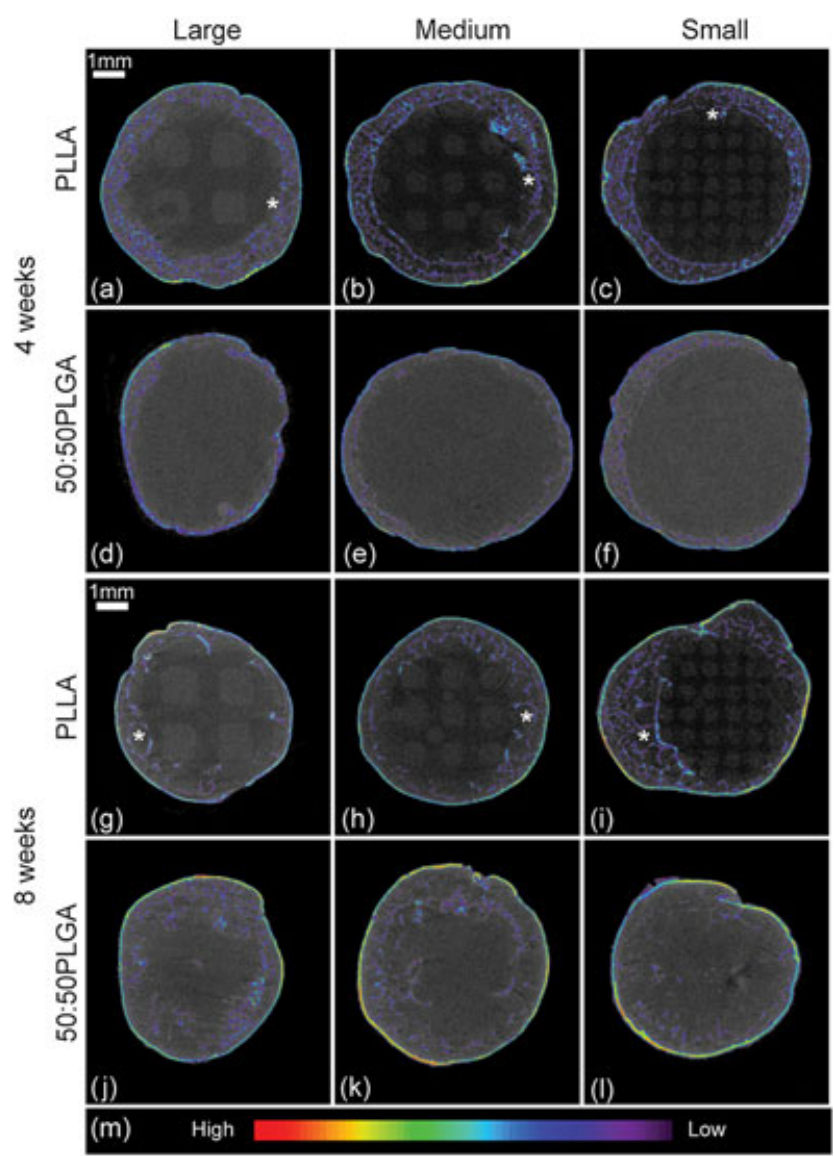

Figure 4. $\mu$-CT images of PLLA (a, b, and c) and 50:50 PLGA scaffolds (d, e, and f) at 4 weeks, and PLLA (g, h, and i) and 50:50 PLGA scaffolds $(\mathrm{j}, \mathrm{k}$, and $\mathrm{l})$ at 8 weeks. Some struts were surrounded by tissues are indicated by *. Relative density of the tissues are indicated with color scale (m)

medium PLLA scaffold groups (Figure 5a). In addition, the large and medium 50:50 PLGA scaffold groups had more mineralized tissues than the large and medium PLLA scaffold groups at 4 weeks (no significant difference). Medium and small PLLA scaffold groups showed slightly higher mineral density than medium and small 50:50 PLGA scaffold groups (Figure 5b). The results of TMD were similar in all groups at both time points, while BV results showed different trends depending on the scaffold materials. Although only the large 50:50 PLGA showed a significant difference (Figures 5c-5d), the trends suggested that PLLA scaffolds lost their BV between the 4- and 8-week time points, while 50:50 PLGA increased BV during that time. In addition, other trends showed that PLLA scaffolds had more BV than 50:50 PLGA scaffolds at the 4-week time point (Figure 5c). However, after 8 weeks implantation, 50:50 PLGA scaffolds showed higher BV (Figure 5 d) (no significant difference).

\subsection{Mechanical properties}

A compressive test was performed to investigate the changes in scaffold mechanical properties during implantation (Figures 6a, 6d). The average mechanical properties of PLLA and 50:50 PLGA scaffolds were $\geq$ $100 \mathrm{MPa}$ prior to implantation. All PLLA scaffolds had significantly decreased mechanical properties after 4 weeks implantation due to polymer degradation (Figure 6a). Then, their mechanical properties were increased or maintained after 8 weeks implantation due to growth of mineralized tissues. All 50:50 PLGA scaffolds had a nearly complete loss of mechanical properties at 4 weeks but then slightly increased after 8 weeks implantation (Figure 6b). The mechanical properties of all 50:50 PLGA scaffolds were significantly lower than small PLLA scaffolds at 4 weeks and medium and small PLLA scaffolds at 8 weeks.

The correlation between the modulus and bone volume are shown in Figures $6 \mathrm{~b}, 6 \mathrm{c}, 6 \mathrm{e}$, and $6 \mathrm{f}$. PLLA scaffolds did not have any correlation at $4\left(R^{2}=0.0371\right)$ and $8\left(R^{2}=0.0102\right)$ weeks. However, 50:50 PLGA scaffolds had some correlation at $4\left(R^{2}=0.4809\right)$ and $8\left(R^{2}=0.4043\right)$ weeks. The 8 -week data had an outlier that lowered the correlation, which increased to $\mathrm{R}^{2}=0.8884$ without the outlier. These results indicate that increased bone deposition increased the moduli of the regenerated tissues when the scaffold modulus was significantly reduced.

\section{Discussion}

In this study, computer based scaffold design and SFF were used to determine the effects of porous scaffold 

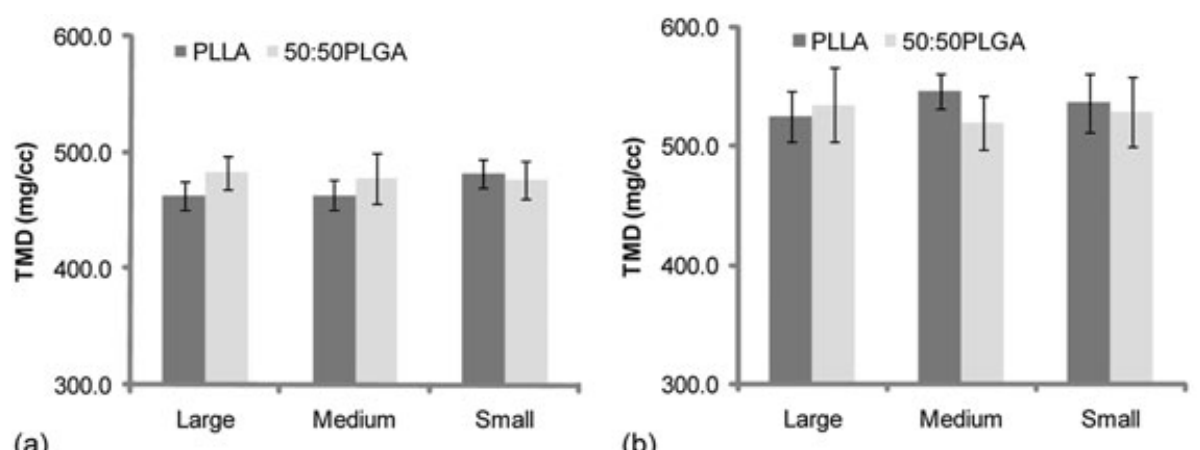

(a)

(b)
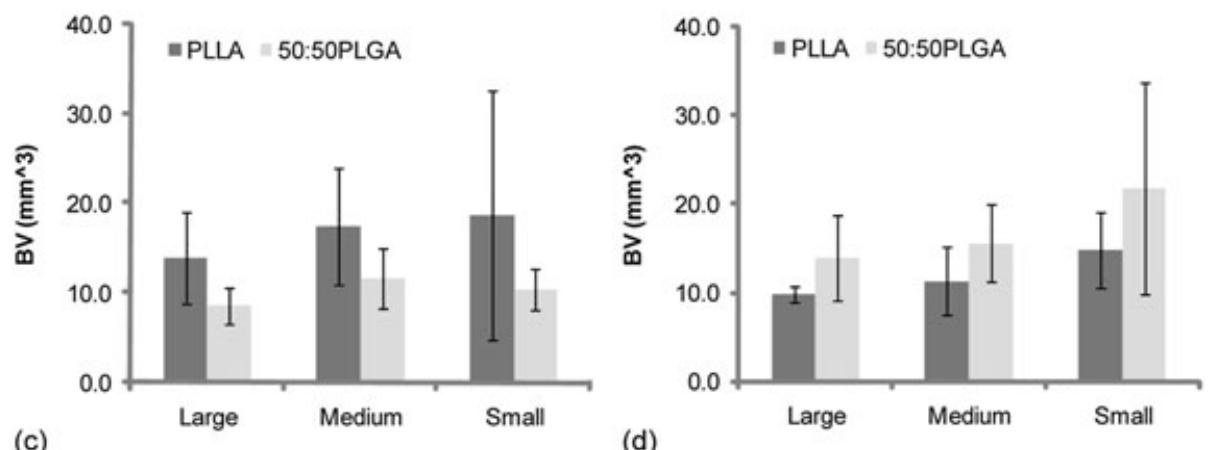

Figure 5. Tissue mineral density (TMD) at 4 (a) and 8 (b) weeks, and Bone volume (BV) at 4 (c) and 8 (d) weeks. There was no significant difference of TMD and BV values between PLLA and 50:50 PLGA scaffolds

Table 2. Tissue mineral density, bone volume and modulus of scaffold and tissue constructs at 4 and 8 weeks

\begin{tabular}{|c|c|c|c|c|c|c|c|}
\hline & & \multicolumn{3}{|c|}{ PLLA } & \multicolumn{3}{|c|}{ 50:50 PLGA } \\
\hline & & Large & Medium & Small & Large & Medium & Small \\
\hline \multirow[t]{2}{*}{$\mathrm{TMD}(\mathrm{mg} / \mathrm{cc})$} & 4 wks & $\begin{array}{c}462.6 \pm 12.4 \\
(N=4)\end{array}$ & $\begin{array}{c}463.4 \pm 12.5 \\
(N=5)\end{array}$ & $\begin{array}{c}482.4 \pm 12.1 \\
(\mathrm{~N}=5)\end{array}$ & $\begin{array}{c}482.8 \pm 14.0 \\
(N=8)\end{array}$ & $\begin{array}{c}477.5 \pm 21.7 \\
(N=7)\end{array}$ & $\begin{array}{c}476.2 \pm 16.4 \\
(N=5)\end{array}$ \\
\hline & 8 wks & $\begin{aligned} & 524.8 \pm 21.4 \\
&(\mathrm{~N}=3)\end{aligned}$ & $\begin{array}{c}546.0 \pm 14.7 \\
(N=5)\end{array}$ & $\begin{array}{c}536.5 \pm 24.4 \\
(N=5)\end{array}$ & $\begin{array}{c}534.5 \pm 31.4 \\
(N=5)\end{array}$ & $\begin{array}{c}519.9 \pm 22.5 \\
(N=5)\end{array}$ & $\begin{array}{c}528.7 \pm 29.2 \\
(N=5)\end{array}$ \\
\hline \multirow{2}{*}{$\begin{array}{l}\text { Bone } \\
\text { Volume } \\
\left(\mathrm{mm}^{3}\right)\end{array}$} & 4 wks & $\begin{array}{c}13.96 \pm 5.14 \\
(N=4)\end{array}$ & $\begin{array}{c}17.37 \pm 6.53 \\
(N=5)\end{array}$ & $\begin{array}{c}18.66 \pm 13.87 \\
(N=5)\end{array}$ & $\begin{array}{c}8.58 \pm 2.08 \\
(\mathrm{~N}=8)\end{array}$ & $\begin{array}{c}11.61 \pm 3.28 \\
(\mathrm{~N}=7)\end{array}$ & $\begin{array}{c}10.39 \pm 2.27 \\
(N=5)\end{array}$ \\
\hline & 8 wks & $\begin{array}{c}9.83 \pm 0.89 \\
(N=3)\end{array}$ & $\begin{aligned} 11.25 & \pm 3.85 \\
(N=5) & =\end{aligned}$ & $\begin{array}{c}14.71 \pm 4.28 \\
(N=5)\end{array}$ & $\begin{array}{c}13.88 \pm 4.76 \\
(N=5)\end{array}$ & $\begin{array}{c}15.55 \pm 4.38 \\
(N=5)\end{array}$ & $\begin{array}{c}21.77 \pm 11.96 \\
(N=5)\end{array}$ \\
\hline \multirow[t]{3}{*}{$\begin{array}{l}\text { Modulus } \\
(\mathrm{MPa})\end{array}$} & 0 wks & $\begin{array}{c}100.4 \pm 56.4 \\
(\mathrm{~N}=7)\end{array}$ & $\begin{array}{c}98.9 \pm 30.6 \\
(\mathrm{~N}=7)\end{array}$ & $\begin{array}{c}196.4 \pm 76.7 \\
(\mathrm{~N}=7)\end{array}$ & $\begin{array}{c}197.8 \pm 53.7 \\
(N=6)\end{array}$ & $\begin{array}{c}239.0 \pm 102.6 \\
(\mathrm{~N}=6)\end{array}$ & $\begin{array}{c}125.1 \pm 63.2 \\
(\mathrm{~N}=5)\end{array}$ \\
\hline & 4 wks & $\begin{array}{c}13.0 \pm 4.2 \\
(N=4)\end{array}$ & $\begin{array}{c}29.4 \pm 14.2 \\
(\mathrm{~N}=4)\end{array}$ & $\begin{array}{c}90.5 \pm 41.7 \\
(\mathrm{~N}=7)\end{array}$ & $\begin{array}{c}0.78 \pm 0.35 \\
(\mathrm{~N}=5)\end{array}$ & $\begin{array}{c}1.30 \pm 0.73 \\
(N=6)\end{array}$ & $\begin{array}{c}0.80 \pm 0.40 \\
(\mathrm{~N}=4)\end{array}$ \\
\hline & 8 wks & $\begin{array}{c}32.2 \pm 31.9 \\
(\mathrm{~N}=3)\end{array}$ & $\begin{array}{c}53.7 \pm 28.1 \\
(N=5)\end{array}$ & $\begin{array}{c}83.4 \pm 27.3 \\
(N=5)\end{array}$ & $\begin{array}{c}5.43 \pm 5.97 \\
(N=5)\end{array}$ & $\begin{array}{c}4.15 \pm 1.79 \\
(N=4)\end{array}$ & $\begin{array}{c}6.62 \pm 3.52 \\
(\mathrm{~N}=4)\end{array}$ \\
\hline
\end{tabular}

material and architecture on bone regeneration. PLLA and 50:50 PLGA scaffolds were fabricated using identical procedures with the exception of their melting temperatures. The semi-crystalline structure of PLLA required a higher casting temperature, while the 50:50 PLGA was melted at a lower temperature than PLLA due to its amorphous structure. $\mu$-CT data demonstrated that the fabricated PLLA and 50:50 PLGA scaffolds had similarly-defined pore sizes, strut sizes, porosities, and surface to volume ratios. In addition, $\mu$-CT results showed that the fabricated scaffolds in the same design groups had identical internal and external architectures between materials. Although the viscosities of the polymers were similar, the surface morphologies of the scaffolds were slightly different, as shown in the ESEM images. This could be due to the difference of the chemical structures including crystallinity of the polymers.

Ex vivo gene therapy was used to induce bone formation from the surrounding tissues at the implant site. This regenerative gene therapy strategy using adenoviral vectors could be applied to transduce various cells such as bone marrow stromal cells (Chang et al., 2003) and fibroblasts (Krebsbach et al., 2000; Hirata et al., 2003). The consistent secretion of BMP-2 from adenovirus transduced HGFs for up to 2 weeks in vitro has been reported (Shin et al., 2010). Additionally, this approach has been studied to induce endochondral-like bone tissue formation by transduced HGFs (Krebsbach et al., 2000; 


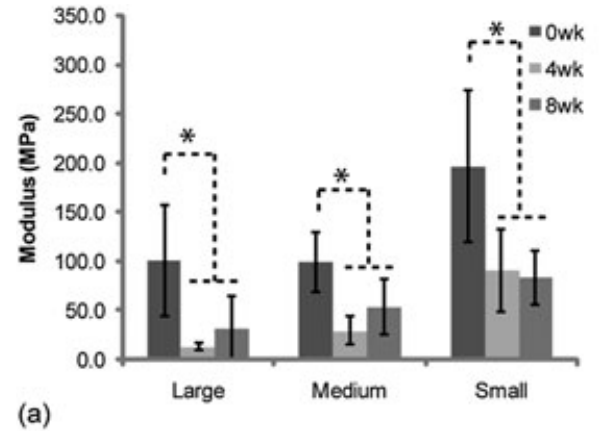

(a)

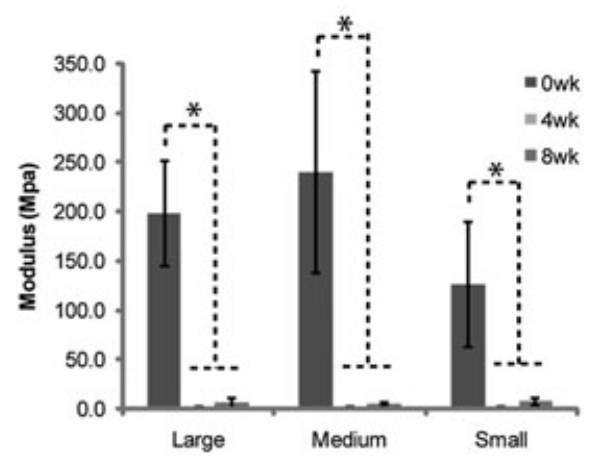

(d)

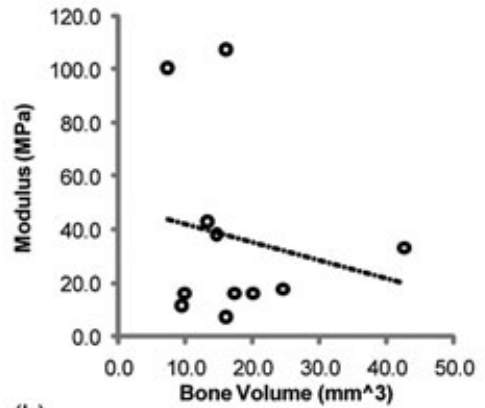

(b)

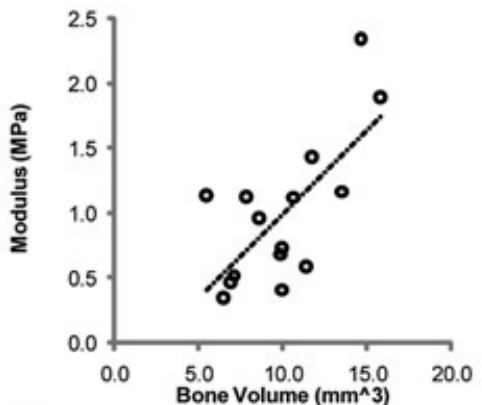

(e)

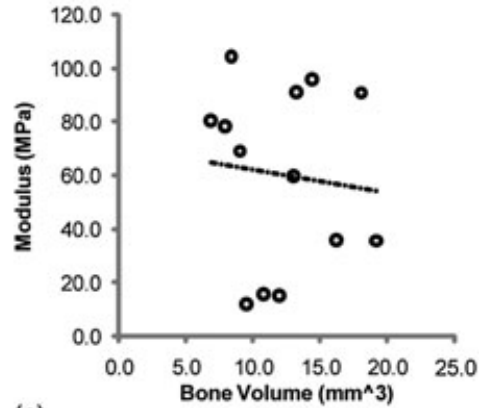

(c)

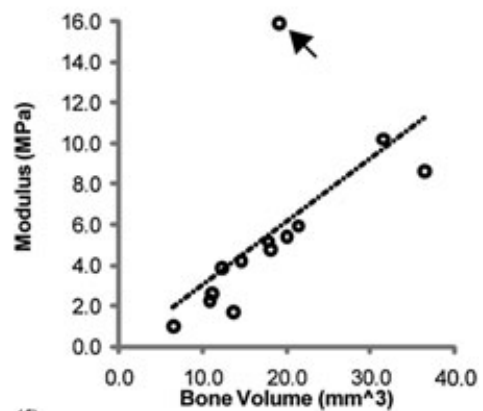

(f)

Figure 6. Mechanical test results of implanted PLLA (a) and 50:50 PLGA (d). * indicates significant difference. Correlations between modulus and bone volume of PLLA scaffolds at 4 (b) and 8 (c) weeks and 50:50 PLGA scaffolds at 4 (e) and 8 (f) weeks. R-square values are 0.0371 (b), 0.0102 (c), 0.4809 (e) and 0.4043 (f). The value of (f) increases to 0.8884 without the outlier (indicated with an arrow)

Rutherford et al., 2002). Other methods of bone formation have previously been reported, including seeding bone marrow stromal cells (Claase et al., 2007), incorporation of BMP-7 into nanospheres (Wei et al., 2007), and BMP-2 conjugated with heparin (Claase et al., 2007). However, these methods require pre-treatment of the scaffolds prior to implantation. The scaffolds could start degrading during the preparation, especially 50:50 PLGA scaffolds, due to their short degradation profile. Therefore, to minimize any alteration of the scaffolds before implantation and to successfully regenerate bone tissue in vivo, ex vivo gene therapy was used as a suitable method for testing in this current study.

Scaffold tissue constructs differed between the PLLA and 50:50 PLGA scaffolds due to polymer degradation. PLLA scaffolds maintained their architecture throughout the study period, while 50:50 PLGA scaffolds completely lost the original designed pore structure, and there were only chunks remaining at the 4-week time point. The hydrophilicity of the PGA component in PLGA could have induced faster water uptake and hydrolysis, leading to faster degradation ( $\mathrm{Lu}$ et al., 2000). In contrast, the methyl group of the PLLA side chain contributed to the hydrophobicity of the polymer, resulting in slower degradation (Ishaug-Riley et al., 1999). As reported previously, the in vivo half-life of 50:50 PLGA foams is about 2 weeks ( $\mathrm{Lu}$ et al., 2000). The 50:50 PLGA scaffolds in the current study maintained their architectures for only a few weeks or less in vivo.
Due to the rapid degradation, little bone tissue was found inside the degraded 50:50 PLGA scaffolds at 4 and 8 weeks. In contrast, the PLLA scaffolds had small amounts of bone ingrowth and some blood vessel-like tissues from the histological analysis. These differences could be attributed to the effects of degradation of by-products on cell activities. PLLA nanofibers or porous membranes supported activities of chondrocytes and human mesenchymal stem cells and vascularization more than those of 50:50 PLGA, since rapid degradation of 50:50 PLGA created acidic environments and prevented cell activities on or in the constructs ( $\mathrm{Li}$ et al., 2006, Kaushiva et al., 2007). In addition, reduction of $\mathrm{pH}$ negatively affected activities of bone marrow stromal cells during osteogenesis (Kohn et al., 2002). Although there are no data regarding $\mathrm{pH}$ change or acidic by-products in the current study, there could be similar effects on cell activities and tissue formation for both PLLA and 50:50 PLGA scaffolds at the earlier time point. Additionally, the collapse of the PLGA porous architecture could inhibit cell migration and bone formation within the scaffold interior.

The trends in BV results show that BV was greater on the PLLA scaffolds than the 50:50 PLGA scaffolds at 4 weeks, while the 50:50 PLGA scaffolds had greater BV at 8 weeks. The acidic environment could also explain the change in bone volume over time. Initially, at 4 weeks, bone formation was inhibited by more acidic by-products in the environment of the PLGA scaffolds, but the removal of these degradation by-products allowed restoration of 
cellular activities, which could have led to the bone volume increase observed at the 8 -week time point. The PLLA scaffolds could have had more degradation byproducts, which would have lowered BV at 8 weeks. From the data shown in this and previous studies (Li et al., 2006: Kaushiva et al., 2007; Kohn et al., 2002), PLLA scaffolds could be more useful in this situation because they have a slower degradation rate that allows new tissue to generate while still maintaining sufficient mechanical properties to support new tissue growth. In comparison, 50:50 PLGA was not able to support the tissue due to its fast degradation profile. It would be useful to study another polymer such as 85:15 PLGA as a SFF scaffold for bone application since it lasts longer in vivo, Furthermore, the effects of SFF scaffolds on degradation need to be further investigated to better understand the interaction between scaffolds and tissue formation.

The PLLA scaffolds in this study showed much less bone ingrowth than porous HA scaffolds and porous poly (propylene fumerate)/tricalcium phosphate (PPF/ TCP) scaffolds reported in previous studies (Schek et al., 2006; Lin et al., 2005), since HA and TCP are known osteoconductive materials that have been shown to allow chemotactic adherence for enhanced bone growth. Furthermore, hydrophobic materials like PLLA could delay cell attachment and bone formation (Oh et al., 2007, Oh et al., 2003). In addition, the layers of tissues or bony shell surrounding the PLLA scaffolds prevented diffusion of nutrients into the construct (Kruyt et al., 2007) and could cause accumulation of acidic by-product inside the implants, which would inhibit cell migration and tissue ingrowth.

The importance of scaffold pore sizes for bone formation has been extensively studied. The $280 \mu \mathrm{m}$ minimum pore size used in the current study was chosen based on the required diameters for blood vessel formation, which were approximated according to in vivo bone tissue formation in previous studies (Kuboki et al., 2001; Oh et al., 2007; Druecke et al., 2004). Although the effect of pore size of PLLA or PLGA porous scaffolds on bone regeneration has been explored in various studies, results have varied depending on the materials and methods used. For example, pore sizes of PLGA scaffolds did not affect osteoblast activities in vitro nor was in vivo bone formation influenced by pore sizes within the range of 150-710 $\mu \mathrm{m}$ and 125-500 $\mu \mathrm{m}$ (Ishaug-Riley et al., 1997; Ishaug-Riley et al., 1998; Wu et al., 2006). In contrast, other studies compared porous PLGA scaffolds with constant porosity and indicated that pore sizes of 400-600 $\mu \mathrm{m}$ were favourable for osteoblasts rather than $300 \mu \mathrm{m}$ or smaller pore sizes (Pamula et al., 2008a; Pamula et al., 2008b). Another study demonstrated that PLLA scaffolds with pores of $350 \mu \mathrm{m}$ diameters induced more bone ingrowth than the smaller ones (100 and $200 \mu \mathrm{m}$ ) when implanted in rabbit calvarias (Robinson et al., 1995). However, it is again important to note that these previous studies, which suggested an influence of pore diameter (Pamula et al., 2008a; Pamula et al., 2008b; Robinson et al., 1995), used conventional fabrication techniques that did not rigorously control pore diameter and interconnectivity. The current study's chosen pore sizes of 280,550 , and $820 \mu \mathrm{m}$ therefore bracketed the range of pore sizes investigated in previous studies; with the difference being the controlled, interconnected, and repeatable architecture used in the current study. The pore range was also within the range of reported trabecular pore sizes of $300 \sim 1000 \mu \mathrm{m}$ (Keaveny et al., 2001; Rezwan et al., 2006).

Regarding bone ingrowth from $\mu$-CT images, this study did not observe any significant differences between the scaffolds designs such as pore size, which is in agreement with previous studies (Schek et al., 2006; Roosa et al., 2010). The distances of bone penetration into the PLLA scaffolds in this study was greater than previously reported in PLGA foams implanted in the rat mesentery for 49 days (Ishaug-Riley et al., 1997). The distances generally increased between 4-8 weeks in the current study, while the previous study showed that there was little increase over implantation time. This could be due to their use of foam scaffolds, which have random oriented pores and non-controlled internal architectures, and a more tortuous pathway that could have prevented nutrient diffusion and cell migration into the scaffolds (Melchels et al., 2010). Silva et al. (2006) showed that porous HA and PLLA scaffolds with aligned channels could improve cell infiltration into the centre of the scaffolds. Their study and the results of the current study indicate that orthogonally interconnected porous architectures might not only help increase nutrient diffusion when compared to foam scaffolds, but could also guide tissue ingrowth.

Other scaffold design parameters such as porosity and surface area did not seem to have a significant effect on bone formation in this current study. Although high porosity has been discussed as an important requirement of scaffolds (Sosnowski et al., 2006), the effect of scaffold porosity on bone formation was not significant in this study. Since the scaffolds used in the current study had fully and orthogonallyinterconnected pore architectures or channels, infiltration of nutrients into the scaffolds might not have been different between the scaffold design groups. The pore sizes of the scaffolds varied the surface areas of the scaffolds onto which cells from host tissues could attach. $\mu$-CT data also showed that the patterns of bone ingrowth followed the internal architectures of the scaffolds. Small PLLA scaffolds had the smallest strut and pore sizes, which allowed the tissues to surround the struts and interlock, thereby increasing tissue integration. This might have helped to form stronger bonds between the regenerated tissues and porous scaffolds. The scaffolds with smaller pores had more total surface area than the scaffolds with larger pores, which might have created a larger surface area for cell adhesion and helped bone formation. Furthermore, another scaffold design parameter could have a greater impact on increasing bone formation. For example, it has been postulated that pore interconnectivity 
and permeability can be an important scaffold design parameter (Melchels et al., 2010; Hui et al., 1996; Jones et al., 2009).

For functional use of scaffolds at load bearing sites, it is important to understand the time dependent changes in scaffold/tissue construct mechanical properties. Initially, the fabricated PLLA and 50:50 PLGA scaffolds had mechanical properties in the low to medium range of human trabecular bone (Saito et al., 2010). After implantation, the mechanical properties decreased due to the degradation of materials. As shown in the histology and $\mu$-CT images, 50:50 PLGA scaffolds completely lost their designed architectures, and their mechanical properties decreased dramatically at both 4 and 8 weeks compared with the pre-implanted scaffolds and PLLA scaffolds. Despite the retention of designed architecture, PLLA scaffolds also showed a decrease in their mechanical properties, which indicated some polymer degradation.

The mechanical properties of PLLA scaffolds with bone tissue were significantly higher than those of 50:50 PLGA scaffolds at 4 and 8 weeks. There was no correlation between bone volume and PLLA/bone construct mechanical properties at 4 and 8 weeks. However, the 50:50 PLGA/bone construct mechanical properties showed some correlation with bone volume at 4 weeks, which increased at 8 weeks. The mechanical properties of the PLLA scaffold constructs, due to the greater retention of polymer architecture and mechanical properties, were likely more dependent on the polymer at 4 and 8 weeks. In contrast, the 50:50 PLGA mechanical properties were solely dependent on the generated bone as the polymer was degraded at 4 weeks.

Although the majority of PLLA mechanical properties relied on the scaffold material, large and medium PLLA scaffolds still exhibited an increasing trend in mechanical properties due to higher mineralized tissues and bone growth on the scaffolds between 4-8 weeks. Small PLLA scaffolds had similar mechanical properties at both time points. Small PLLA scaffolds might have had a slower degradation speed, thereby maintaining their mechanical properties longer than the other groups.

One of the limitations of this study is that ectopic sites did not provide the same environment as orthotopic sites, including mechanical stimulation, nutrients, cell types, and cell-cell interactions. For example, the bone volume of PLLA scaffolds decreased between weeks 4 and 8, similar to findings by Lin et al. (Lin et al., 2005). This could be because there was little loading on the ectopic models to simulate bone remodeling and increases in mineralization of newly formed tissues (Duty et al., 2007) and less nutrient supply. In addition, mechanical loading on the scaffolds would have increased the degradation of PLLA scaffolds in terms of molecular weight and mechanical properties (Kang et al., 2009).

\section{Conclusions}

This study compared the effects of material and architectures of porous scaffolds on bone formation. Results showed that material choice significantly influenced in vivo bone tissue regeneration and mechanical properties. It was also observed that scaffold architecture controls the patterns of bone ingrowth and mechanical properties of scaffold-bone constructs. The 50:50 PLGA scaffolds degraded rapidly, providing little initial support for bone ingrowth, and had very low mechanical properties. In comparison, the PLLA scaffolds maintained their architecture throughout the study period and supported some blood vessel and bone ingrowth. Given the long tissue regeneration time observed in many clinical applications (e.g., spine fusion, long bone defects, mandibular defects), the ability of a polymer scaffold to maintain structural and mechanical properties up to 6 months is critical. Pore size, when architecture is maintained and does not collapse, does not significantly influence bone regeneration. The patterns of bone tissue ingrowth were defined by the computer designed pores and struts of the scaffolds. Furthermore, mechanical properties of implanted scaffolds were controlled by the initial architectures. These results support the importance of choosing suitable scaffold materials and designing conductive scaffold architectures that are ideal for bone tissue regeneration. Each of these factors needs to be fine-tuned to find the desired properties for specific anatomical sites or defects.

\section{Acknowledgments}

This study was supported by National Institute of Health (NIH) R01 grant AR 053379.

\section{References}

Athanasiou KA, Agrawal CM, Barber FA, et al. 1998; Orthopaedic applications for PLAPGA biodegradable polymers. Arthroscopy 14: 726-737.

Bessa PC, Casal M, Reis RL. 2008a; Bone morphogenetic proteins in tissue engineering: the road from laboratory to clinic, part II (BMP delivery). J Tissue Eng Regen Med 2: 81-96.

Bessa PC, Casal M, Reis RL. 2008b; Bone morphogenetic proteins in tissue engineering: the road from the laboratory to the clinic, part I (basic concepts). $J$ Tissue Eng Regen Med 2: 1-13.

Cao Y, Mitchell G, Messina A, et al. 2006; The influence of architecture on degradation and tissue ingrowth into threedimensional poly(lactic-co-glycolic acid) scaffolds in vitro and in vivo. Biomaterials 27: 2854-2864.

Chang SC, Chuang HL, Chen YR, et al. 2003; Ex vivo gene therapy in autologous bone marrow stromal stem cells for tissueengineered maxillofacial bone regeneration. Gene Ther 10: 2013-2019.

Claase MB, de Bruijn JD, Grijpma DW, et al. 2007; Ectopic bone formation in cellseeded poly(ethylene oxide)/poly(butylene terephthalate) copolymer scaffolds of varying porosity. J Mater Sci Mater Med 18: 1299-1307.

Druecke D, Langer S, Lamme E, et al. 2004; Neovascularization of poly (ether ester) 
block-copolymer scaffolds in vivo: longterm investigations using intravital fluorescent microscopy. J Biomed Mater Res A 68: 10-18.

Duty AO, Oest ME, Guldberg RE. 2007; Cyclic mechanical compression increases mineralization of cell-seeded polymer scaffolds in vivo. J Biomech Eng 129: 531-539.

Franceschi RT, Wang D, Krebsbach PH, et al. 2000; Gene therapy for bone formation in vitro and in vivo osteogenic activity of an adenovirus expressing BMP7. $J$ Cell Biochem 78: 476-486.

Goldstein AS, Zhu G, Morris GE, et al. 1999; Effect of osteoblastic culture conditions on the structure of poly(DL-lactic-co-glycolic acid) foam scaffolds. Tissue Eng 5: 421-434.

Gomes ME, Holtorf HL, Reis RL, et al. 2006; Influence of the porosity of starch-based fiber mesh scaffolds on the proliferation and osteogenic differentiation of bone marrow stromal cells cultured in a flow perfusion bioreactor. Tissue Eng 12: 801-809.

Hirata K, Tsukazaki T, Kadowaki A, et al. 2003; Transplantation of skin fibroblasts expressing BMP-2 promotes bone repair more effectively than those expressing Runx2. Bone 32: 502-512.

Hollister SJ. 2005; Porous scaffold design for tissue engineering. Nat Mate 4: 518-524.

Hollister SJ, Levy RA, Chu TM, et al. 2000; An image-based approach for designing and manufacturing craniofacial scaffolds. Int J Oral Maxillofac Surg 29: 67-71.

Hollister SJ, Maddox RD, Taboas JM. 2002; Optimal design and fabrication of scaffolds to mimic tissue properties and satisfy biological constraints. Biomaterials 23: 4095-4103.

Hsu SH, Yen HJ, Tseng CS, et al. 2007; Evaluation of the growth of chondrocytes and osteoblasts seeded into precision scaffolds fabricated by fused deposition manufacturing. J Biomed Mater Res B Appl Biomater 80: 519-527.

Hui PW, Leung PC, Sher A. 1996; Fluid conductance of cancellous bone graft as a predictor for graft-host interface healing. J Biomech 29: 123-132.

Hutmacher DW. 2001; Scaffold design and fabrication technologies for engineering tissues--state of the art and future perspectives. J Biomater Sci Polym Ed 12: 107-124.

Hutmacher DW, Schantz T, Zein I, et al. 2001; Mechanical properties and cell cultural response of polycaprolactone scaffolds designed and fabricated via fused deposition modelling. J Biomed Mater Res 55: 203-216.

Hutmacher DW, Sittinger M, Risbud MV. 2004; Scaffold-based tissue engineering: rationale for computer-aided design and solid free-form fabrication systems. Trends Biotechnol 22: 354-362.

Ishaug-Riley SL, Crane GM, Gurlek A, et al. 1997; Ectopic bone formation by marrow stromal osteoblast transplantation using poly(DL-lactic-co-glycolic acid) foams implanted into the rat mesentery. $J$ Biomed Mater Res 36: 1-8.

Ishaug-Riley SL, Crane-Kruger GM, Yaszemski MJ, et al. 1998; Three-dimensional culture of rat calvarial osteoblasts in porous biodegradable polymers. Biomaterials 19: 1405-1412.

Ishaug-Riley SL, Okun LE, Prado G, et al. 1999; Human articular chondrocyte adhesion and proliferation on synthetic biodegradable polymer films. Biomaterials 20: 2245-2256.

Jones AC, Arns CH, Hutmacher DW, et al. 2009; The correlation of pore morphology, interconnectivity and physical properties of $3 \mathrm{D}$ ceramic scaffolds with bone ingrowth. Biomaterials 30: 1440-1451.

Kang Y, Yao Y, Yin G, et al. 2009; A study on the in vitro degradation properties of poly (L-lactic acid)/beta-tricalcuim phosphate (PLLA/beta-TCP) scaffold under dynamic loading. Med Eng Phys 31: 589-594.

Karageorgiou V, Kaplan D. 2005; Porosity of 3D biomaterial scaffolds and osteogenesis. Biomaterials 26: 5474-5491.

Kaushiva A, Turzhitsky VM, Darmoc M, et al. 2007; A biodegradable vascularizing membrane: a feasibility study. Acta Biomater 3: 631-642.

Keaveny TM, Morgan EF, Niebur GL, Yeh OC. 2001; Biomechanics of trabecular bone. Annu Rev Biomed Eng 3: 307-333.

Khan Y, Yaszemski MJ, Mikos AG, et al. 2008; Tissue engineering of bone: material and matrix considerations. $J$ Bone Joint Surg Am 90 Suppl 1: 36-42.

Kohn DH, Sarmadi M, Helman JI, et al. 2002; Effects of $\mathrm{pH}$ on human bone marrow stromal cells in vitro: implications for tissue engineering of bone. $J$ Biomed Mater Re 60: 292-299.

Kontakis GM, Pagkalos JE, Tosounidis TI, et al. 2007; Bioabsorbable materials in orthopaedics. Acta Orthop Belg 73: 159-169.

Krebsbach PH, Gu K, Franceschi RT, et al. 2000; Gene therapy-directed osteogenesis: BMP-7-transduced human fibroblasts form bone in vivo. Hum Gene Ther 11: 1201-1210.

Kruyt MC, Dhert WJ, Oner FC, et al. 2007; Analysis of ectopic and orthotopic bone formation in cell-based tissue-engineered constructs in goats. Biomaterials 28: 1798-1805.

Kuboki Y, Jin Q, Takita H. 2001; Geometry of carriers controlling phenotypic expression in BMP-induced osteogenesis and chondrogenesis. J Bone Joint Surg Am 83-A Suppl 1: S105-S115

Li JP, Habibovic P, van den Doel M, et al. 2007; Bone ingrowth in porous titanium implants produced by 3D fiber deposition. Biomaterials 28: 2810-2820.

Li WJ, Cooper JA Jr, Mauck RL, et al. 2006; Fabrication and characterization of six electrospun poly(alpha-hydroxy ester)-based fibrous scaffolds for tissue engineering applications. Acta Biomater 2: $377-385$

Lin CY, Kikuchi N, Hollister SJ. 2004; A novel method for biomaterial scaffold internal architecture design to match bone elastic properties with desired porosity. J Biomech 37: 623-636.

Lin CY, Schek RM, Mistry AS, et al. 2005; Functional bone engineering using ex vivo gene therapy and topology-optimized, biodegradable polymer composite scaffolds. Tissue Eng 11: 1589-1598.

Lu L, Peter SJ, Lyman MD, et al. 2000; In vitro and in vivo degradation of porous poly (DL-lactic-co-glycolic acid) foams. Biomaterials 21: 1837-1845.

Martins A, Chung S, Pedro AJ, et al. 2009; Hierarchical starch-based fibrous scaffold for bone tissue engineering applications. Tissue Eng Regen Med 3: 37-42.
Melchels FP, Barradas AM, van Blitterswijk CA, et al. 2010; Effects of the architecture of tissue engineering scaffolds on cell seeding and culturing. Acta Biomater 6: 4208-4217.

Middleton JC, Tipton AJ. 2000; Synthetic biodegradable polymers as orthopedic devices. Biomaterials 21: 2335-2346.

Narayan D, Venkatraman SS. 2008; Effect of pore size and interpore distance on endothelial cell growth on polymers. $J$ Biomed Mater Res A 87: 710-718.

Nussenbaum B, Krebsbach PH. 2006; The role of gene therapy for craniofacial and dental tissue engineering. Adv Drug Deliv Rev 58: 577-591.

Oh SH, Kang SG, Kim ES, et al. 2003; Fabrication and characterization of hydrophilic poly(lactic-co-glycolic acid)/poly(vinyl alcohol) blend cell scaffolds by melt-molding particulate-leaching method. Biomaterials 24: 4011-4021.

Oh SH, Park IK, Kim JM, et al. 2007; In vitro and in vivo characteristics of PCL scaffolds with pore size gradient fabricated by a centrifugation method. Biomaterials 28: 1664-1671.

Pamula E, Bacakova L, Filova E, et al. 2008a; The influence of pore size on colonization of poly(L-lactide-glycolide) scaffolds with human osteoblast-like MG 63 cells in vitro. $J$ Mater Sci Mater Med 19: 425-435.

Pamula E, Filova E, Bacakova L, et al. 2008b; Resorbable polymeric scaffolds for bone tissue engineering: The influence of their microstructure on the growth of human osteoblast-like MG 63 cells. J Biomed Mater Res A 89(2): 432-443.

Rezwan K, Chen QZ, Blaker JJ, et al. 2006; Biodegradable and bioactive porous polymer/inorganic composite scaffolds for bone tissue engineering. Biomaterials 27: 3413-3431.

Robinson BP, Hollinger JO, Szachowicz EH, et al. 1995; Calvarial bone repair with porous D,L-polylactide. Otolaryngol Head Neck Surg 112: 707-713.

Roosa SM, Kemppainen JM, Moffitt EN, et al. 2010; The pore size of polycaprolactone scaffolds has limited influence on bone regeneration in an in vivo model. $J$ Biomed Mater Res A 92: 359-368.

Rose FR, Cyster LA, Grant DM, et al. 2004; In vitro assessment of cell penetration into porous hydroxyapatite scaffolds with a central aligned channel. Biomaterials 25: 5507-5514.

Rutherford RB, Moalli M, Franceschi RT, et al. 2002; Bone morphogenetic proteintransduced human fibroblasts convert to osteoblasts and form bone in vivo. Tissue Eng 8: 441-452.

Rutherford RB, TrailSmith MD, Ryan ME, et al. 1992; Synergistic effects of dexamethasone on platelet-derived growth factor mitogenesis in vitro. Arch Oral Biol 37: 139-145.

Saito E, Kang H, Taboas JM, et al. 2010; Experimental and computational characterization of designed and fabricated 50:50 PLGA porous scaffolds for human trabecular bone applications. J Mater Sci Mater Med 21: 2371-2383.

Schek RM, Wilke EN, Hollister SJ, et al. 2006; Combined use of designed scaffolds and adenoviral gene therapy for skeletal tissue engineering. Biomaterials 27: 1160-1166. 
Shin JH, Kim KH, Kim SH, et al. 2010; Ex vivo bone morphogenetic protein-2 gene delivery using gingival fibroblasts promotes bone regeneration in rats. $J$ Clin Periodontol 37: 305-311.

Silva MM, Cyster LA, Barry JJ, et al. 2006; The effect of anisotropic architecture on cell and tissue infiltration into tissue engineering scaffolds. Biomaterials 27: 5909-5917.

Sinha RK, Morris F, Shah SA, et al. 1994; Surface composition of orthopaedic implant metals regulates cell attachment, spreading, and cytoskeletal organization of primary human osteoblasts in vitro. Clin Orthop Relat Res (305): 258-272.
Sosnowski S, Wozniak P, LewandowskaSzumiel M. 2006; Polyester scaffolds with bimodal pore size distribution for tissue engineering. Macromol Biosci 6: 425-434. Sun W, Starly B, Darling A, et al. 2004; Computer-aided tissue engineering: application to biomimetic modelling and design of tissue scaffolds Biotechnol Appl Biochem 39: 49-58.

Taboas JM, Maddox RD, Krebsbach PH, et al. 2003; Indirect solid free form fabrication of local and global porous, biomimetic and composite 3D polymer-ceramic scaffolds. Biomaterials 24: 181-194.

Tsuruga E, Takita H, Itoh H, et al. 1997; Pore size of porous hydroxyapatite as the cell-substratum controls BMP-induced osteogenesis. J Biochem 121: 317-324.

Wei G, Jin Q, Giannobile WV, et al. 2007; The enhancement of osteogenesis by nanofibrous scaffolds incorporating rhBMP-7 nanospheres. Biomaterials 28: 2087-2096. Williams JM, Adewunmi A, Schek RM, et al. 2005; Bone tissue engineering using polycaprolactone scaffolds fabricated via selective laser sintering. Biomaterials 26: 4817-4827.

Wu YC, Shaw SY, Lin HR, et al. 2006; Bone tissue engineering evaluation based on rat calvaria stromal cells cultured on modified PLGA scaffolds. Biomaterials 27: 896-904. 